DOI: https://doi.org/10.34069/AI/2021.43.07.6

How to Cite:

Dmitriev, O.N., \& Zolotova, V.A.. (2021). Concept to recognize crisis of organizational and institutional separation by Artificial Intelligence System. Amazonia Investiga, 10(43), 59-71. https://doi.org/10.34069/AI/2021.43.07.6

\title{
Concept to recognize crisis of organizational and institutional separation by Artificial Intelligence System
}

\section{Концепция признания кризиса организационного и институционального разделения с помощью системы искусственного интеллекта}

\author{
Received: May 21, $2021 \quad$ Accepted: July 16, 2021
}

Written by:

Oleg N. Dmitriev20

https://orcid.org/0000-0003-4514-7519

https://www.scopus.com/authid/detail.uri?origin=AuthorProfile\&authorId=57202382529

Veronika A. Zolotova ${ }^{21}$

https://orcid.org/0000-0001-9266-6923

https://www.scopus.com/authid/detail.uri?authorId=57202382627

\begin{abstract}
The sphere of anti-crisis management is highlighted in relation to the open variety of organizational and institutional separations that are typical for the higher forms of industrial and post-industrial economies. This article shows the typicity and relevance of critical management situations associated with the emergence of crises. Furthermore, it justifies the objective orientation to a dense (not sparse) stream of crisis situations requiring identification, ranking, and classification. A strict management interpretation of the separation crisis is given through an assessment of the nature of the dynamics of the separation state indexes. Also, the document presents a generalized typological classification of crises. This article shows the necessity of using a high-level Artificial Intelligence System for this purpose, an indispensable component of which is the classification component.
\end{abstract}

Keywords: Artificial Intelligence, classification of crises, crisis; economy, machine reasoning, organizational and institutional separation.

\begin{abstract}
Аннотация
Выделена сфера антикризисного управления применительно к открытому многообразию организационно-институциональных обособлений, характерных для высших форм индустриальной и для постиндустриальной экономик. Показана типичность и релевантность критических управленческих ситуаций, связанных с возникновением кризисов. Обоснована объективная ориентированность на плотный (не разреженный) поток кризисных ситуаций, требующих выявления, ранжирования и классификации. Дана строгая управленческая интерпретация кризиса обособления через оценку характера динамики показателей состояния обособления. Представлена обобщённая типологическая классификация кризисов. Показана обязательность применения для этого высокоуровневой системы искусственного интеллекта, непременной компонентой которой является классификационная компонента.
\end{abstract}

\begin{tabular}{|c|c|c|}
\hline Ключевые & слова: & экономика, \\
\hline организацион & но-институцион & льное \\
\hline $\begin{array}{l}\text { обособление, } \\
\text { кризисов, }\end{array}$ & $\begin{array}{c}\text { кризис, } \\
\text { искусственный }\end{array}$ & $\begin{array}{r}\text { классификация } \\
\text { интеллект, }\end{array}$ \\
\hline
\end{tabular}

\footnotetext{
${ }^{20}$ Doctor in Economic Sciences, PhD in Engineering Sciences, Professor, Moscow Aviation Institute (National Research University), Moscow, Russia.

${ }^{21}$ Senior Lecturer, Moscow Aviation Institute (National Research University), Moscow, Russia.
} 


\section{Introduction}

One of the main reasons for obtaining insufficiently high or even unacceptable results of the functioning and development of various components of the modern economy is the emergence of crises of different nature, which are generated by several causes and manifest themselves in very diverse forms. Therefore, the need to characterize the managed object from the point of view of its properties with respect to getting it into a crisis situation is very significant and, at the same time, unclaimed. Objectively and without fail, any management subject in the economy at the macro-level, meso-level, and micro- level needs a systematic idea of the basic properties of the managed object, through the prism of which the crisis situation and anti-crisis measures are reflected, with respect to which the state indexes of the corresponding managed object are sensitive.

The relevant objects as applied to the macro-level economies of national (state) and union societies such as the European Community; meso-level, including industries, various territorial. and industrial complexes, so-called economic clusters, corporate groups such as holdings that are now singled out by some experts; micro-level (enterprises and their structural divisions of various hierarchical levels). All of them allow generalization as a kind of group (Dmitriev \& Novikov, 2018b; Dmitriev \& Dergunov, 2004; Dmitriev \& Novikov, 2017; Dmitriev \& Novikov, 2019b) or individual organizational and institutional separation (the latter is considered as traditional, for example, often as a subject of legal relations such as a legal entity or pseudo-entity as a structural unit of an enterprise (Dmitriev \& Dergunov, 2004; Kanashchenkov, Dmitriev, Koval'kov, Dergunov \& Minaev, 2005).

A statement of the existence of a crisis of organizational and institutional separation fundamentally transforms the managing system that manipulates it in terms of goals, prohibitions, managerial influences, etc. The crisis state of separation from normal functioning can be separated only by the properties of this separation as an object.

In most cases, research, development, and practice of anti-crisis management (sometimes abbreviated as crisis management) are oriented:

- $\quad$ for rarely emerging crises;
- to catastrophic and obvious crises such as apparent bankruptcy, which have almost arisen;

- for some empirical anti-crisis programs, which in a significant number of cases give high chances of rectifying the situation, but mainly in the short term and in conditions of external favors.

However, in modern conditions, the nature of the economy and more broadly, societies have already changed significantly and the rigid assumptions listed above do not correspond to managerial realities and, accordingly, are ineffective.

Therefore, there is an objective need for the introduction of crisis detection tools, which allow to identify:

- the expected occurrence of a separation crisis in its broad interpretation (identification of a crisis that has already taken place is almost a failure of separation management, which is evident from the foundations of the general theory of control, which stipulates that the degree of astatism of the managing system must be higher than the level of astatism of the managed object);

- the nature of the crisis and thereby correctly adapt the control system, external or internal with respect to isolation, setting it to prevent, alleviate and eliminate the consequences of the isolation crisis.

Unfortunately, such tools were not identified in the sources available for analysis. Local suggestions in this area do not close the problem.

Meanwhile, the most recent events show how important it is to recognize crisis and even precrisis situations.

For example, large-scale unrecognized preemptive crises were, in particular:

- accident at the Chernobyl' nuclear power plant near the Soviet city Pripyat' in 1986, caused by gross errors of technical personnel during an adventurous experiment to disperse the reactor;

- global economic crisis, correlated with 2008 , caused primarily by the problem of liquidity of derivative securities and the intensification of insufficiently secured lending; 


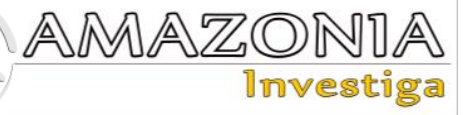

- accident at the Russian SayanoShushenskaya hydro-power plant on the border of the Krasnoyarsk territory and Khakassia in 2009, which occurred as a result of not fully clarified reasons;

- flooding of computer hard disk drive (HDD) manufacturing plants in Thailand in 2011;

- accident at a nuclear power plant in Japan in city Fukushima - Fukushima Daiichi in 2011, caused by a tsunami and largely due to the inability of the cooling system to damage the power system;

- various types of military and economic conflicts and other so-called hybrid interstate conflicts and exacerbations that were typical for the last ten-year period of world history. A typical example of this is the attack by a squad of unidentified unmanned aerial vehicles on a primary oil processing plant near the village of Abqaiq and on an oil refinery at the Khurais oil field in Saudi Arabian at 2019;

- $\quad$ epidemic outbreak of coronavirus in China at 2019-2020 and all over the world afterwards.

All these crises were characterized by a combination of a complex of crisis-forming factors, catastrophism, and the presence of a powerful projection in the economic field as an aftereffect. This projection affected both macroseparations, mezoseparations, and microseparations.

Medium-and small-scale crises have become almost a daily occurrence in the modern world.

Therefore, we are going to consider the problem of recognizing the onset of crises in modern conditions, focusing on economic crises, especially since the tools for recognizing them are quite specific, for example, in comparison with the tools for recognizing natural and manmade crises, again necessarily manifested in the financial and economic space and often initiated by factors of the same nature (for example, the clash of interests of financial and economic parties).

Crises in modern conditions are characterized by multiplicity and synergy. That is, the typical flow of crises is intense and extraordinary, they are heterogeneous and their origin is due to the influence of a set of factors. Accordingly, classical methods suitable for sporadic and rare changes in the environment are used rarely. Moreover, managerial situations, as a rule, are time trouble situations. Therefore, on the one hand, there is no doubt that the conceptual scheme of the feasibility study of anti-crisis solutions is mandatory. On the other hand, classical man-machine control procedures become of little use, since their implementation in the sub-real time mode turns out to be physically impracticable.

The way out of the noted contradiction is seen in the transition to procedures correlated with the so-called artificial intelligence.

The artificial intelligence system should be fully functional (at least implement the functions of assessing predicted crisis situations, analyzing their causality and developing recommendations for their prevention and / or relief). In this sense, there are quite close analogies between artificial intelligence systems and hybrid systems from the categories of information advisors and information controllers - intelligent - DSS environments (Dmitriev, 2017). In this sense, decision-makers are assigned the role of authorizing or vetoing subjects, which can be included in the control loop only in some problem situations.

\section{Literature Review}

We have to admit that the world has already gained considerable experience in forecasting crisis situations in various fields, including partially in the field of economics.

Among the most actively studied areas in this aspect should be mentioned:

- the scope of alerts about natural disasters such as volcanic eruptions, earthquakes, occurrence of tsunamis, typhoons, droughts, floods, etc.;

- $\quad$ the scope of military threat assessment;

- the scope of forecasting economic crises at the macroeconomic level (primarily global and sectoral stock and financial ones).

With regard to management at the level of corporate groupings and enterprises, it is worth highlighting:

- risk-management (Badalova, 2006). However, in contrast, from, for example, in another work (Dmitriev, 2005; Dmitriev; 2018a), risks are unjustifiably broadly, avoiding their correct presentation as expected probable economic losses;

- traditional crisis (or anti-crisis) management (Bazhutin, 2009; Lapenkov, 2001; Minaev and Panagushin, 1998; Nagornov, 2008; Popov, 2005; Solodukhin, 2008; 
Tsvikilevich, 2009; Yankovskaya, 2009), aimed at the formation of priority and quite stereotypical measures for the financial rehabilitation of bankrupt enterprises such as debt restructuring, cost-saving measures, budget support in various forms, etc.;

- controlling (Danilochkina, 2001; Fal'ko and Boyko, 2019; Fal'ko et al., 2019), which allows in many cases to identify primarily the causality of an existing or expected situation.

However, in all cases, in all these studies, the share of the empirical-expert component is unacceptably high. The errors of anti-crisis management are frequent and catastrophic. Anticrisis management, as a rule, instead of standby mode, is in shutdown mode with emergency and impromptu updating.

A more detailed description of well-known developments in areas related to anti-crisis management is given in (Zolotova, 2017).

However, there are the following specific characteristics of this reserve:

- focus on quantitative forecasts for an extremely short period of time;

- focus on empirical expert forecasting methods mainly of the scenario type;

- low level of justification for forecast estimates, both in terms of the presence of crises and their nature;

- orientation in the context of the economy to the only type of separations: concerning enterprises.

Quite a long time ago it was shown (Wiener, 1983; Forrestor, 1971; Dmitriev and Zolotova, 2020) that a fully functional control loop is mandatory. Taking into account the fact that during management it is obligatory to take into account crises, and the implementation of all five classical management functions is required.

In terms of fully functional Artificial Intelligence Systems (often - AI-system), the information situation is the following.

A review of scientific developments leads to the identification of a certain information base of various special cases of considering the possibilities of applying methods and techniques, correlated with creation and use of intelligent computer programs in the design of managing systems using agents (Jons, 2018; Kulikovskiy and Petrov, 2008; Russell and Norvig, 2018). A significant difference in the development of such systems is the emphasis on which the authors focus. In studies (Grishin and Timirgaleeva, 2016; Biryukov, 2015), it is proposed to focus on methods of designing a managing system, mainly by methods of a neural network approach. In (Pershina and Daragan, 2018), it is proposed to focus on the application of Big Data processing technologies as an artificial intelligence technology. In publication (Kuznetsova et al., 2016), it is proposed to prioritize the separation of managed objects and to develop Artificial Intelligence Systems for each group.

In the field of anti-crisis management, there are cautious conclusions about the possibility of using some methods and technologies of artificial intelligence. In (Guruva, 2019), the use of artificial intelligence is given in relation to the implementation of some management functions in the distribution of state subsidies allocated by the Government of the Russian Federation for the reorganization of enterprises to prevent further bankruptcy. In (Butrova, 2021), there are separate descriptions of the use of artificial intelligence in anti-crisis management and also the outline of anti-crisis management. The authors' reasoning and conclusions are reduced to practical examples of the development of software systems applicable in a crisis situation (Zykov, 2016; Zykov; 2018).

IJDSST Special Issue on "AI for Intelligent Decision Support Systems" (Delibašić et al., 2021) includes selected papers from the 5th EWG-DSS International Conference on Decision Support System Technology (EmC-ICDSST 2019 - the Euro International Mini Conference on Decision Support System Technology) held in Madeira, Portugal, 2019, and the 30th European Conference on Operational Research (EURO 2019) held in Dublin, Ireland. However, they affect rather local areas of management and use of artificial intelligence tools.

Summarizing the above mentioned, it can be stated that the massiveness of publications on the prospects for the use of artificial intelligence in full-featured managing systems is combined with the absence of such full-featured systems in modern scientific publications.

First of all, the following conclusions follow from this analysis:

- Artificial Intelligence Systems are, as a category of an intellectual product, rather at the initial stage of development;

- their application is generally assessed as productive; 


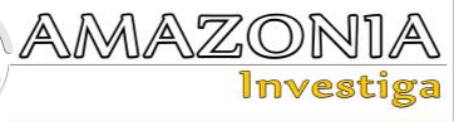

- they are focused more on recognizing managerial situations and scenario options for their development on a given set or in given ranges, to a lesser extent on ranking, and limitedly on responding (for example, it is implemented in the unmanned control system on cars like Tesla). The peculiarity of organizational and institutional segregations is that their functioning, as a rule, cannot be "suspended," especially since their crisis will continue to develop even with such a suspension;

- experience of using Artificial Intelligence Systems in the field of crisis management is very limited.

\section{Theoretical Basis}

When forming reform proposals, we should proceed from the fact that in the field of operating organizational and economic separations, informational-consulting and informationalmanaging systems should be used.

Therefore, for the declared thematic conceptual constructions it was considered expedient to use a multidisciplinary theoretical complex, including the following theories and scientific direction:

- $\quad$ system analysis;

- $\quad$ general control (management) theory;

- operations research;

- organization theory;

- theory of institutional and organizational design;

- optimization theory,

- artificial intelligence theory, etc.

Thus, in theoretical terms, the study was carried out at the "junction of sciences".

\section{Methodology}

The concept is a schematic representation of the methodology. The concept can have a different degree of elaboration of the components. When forming a concept, the most critical, key points are usually worked out and presented.

Accordingly, when forming the methodology and concept, the following research stages are implemented:

- formation of requirements for the methodology;

- analysis of existing methodological or conceptual prototypes for their full-scale or component applicability;
- $\quad$ structuring the concept or methodology with the allocation of priority and at the same time non-obvious components;

- disclosure of critical methodological or conceptual components.

As a rule, the way the concept is presented is determined primarily by the subjective views of the authors.

At the same time, the methodology as a standard component of the managing system is more complete and more strictly structured.

Therefore, in this case, we are talking about the methodology of forming a methodology or concept.

Unfortunately, there are practically no such methodologies available in the available sources. Rather, the exception is a number of publications in the field of methodology synthesis.

So, for example, structural interpretation of universal management methodology is presented, in particular, in (Dmitriev, Yekshembiev, Kh., Lubaeva, Koval'kov, Ju. \& Minaev, 2013; Dmitriev, Novikov, 2019; Cherner, 2020).

Dmitriev, O. N., Yekshembiev, S. Kh., Lubaeva, J. I., Koval'kov, Ju. A., \& Minaev.

Design allows interpretation the anti-crisis management as a local version of management.

\section{Results}

\section{Criticality of crises in the modern era}

A lot of the separations over all the world is not managerially prepared for crisis situations. In the best case, there is a protracted adaptation and a long "creep out" of the crisis.

The dominant part of managing systems is focused on:

- laminar implementation of industrial and economic activities;

- low dynamism of the managerial environment;

- sufficiency or redundancy of management resources;

- significant remoteness of the state from the crisis area (they objectively have or subjectively see some large "margin of safety"). 
At the same time, crises in a developed economy (it is now fashionable to single out certain 4th, 5th and similar structures or levels of industrialization), as well as during the transition to the post-industrial era, are characterized by consequences in the form of unacceptable damage, which also cause severe mass psychological trauma of a prolonged nature.

In a number of studies (Dmitriev, Yekshembiev, Lubaeva, Koval'kov \& Minaev, 2013; Demchenko, 2011), it has been calculated that a high-tech enterprise may experience a severe crisis with rather insignificant fluctuations affecting external or internal factors at the level of $1-3 \%$.

In addition, the modern economy is very closely integrated both at the national level and at the international level, along with the presence of, if not natural monopoly producers of goods, then those of them that determine the strategic situation (Dmitriev, 2018). Therefore, the occurrence of the so-called induced crises that give rise to the phenomena of "crisis dominoes" is quite likely. A good example of this phenomenon is the situation with the stock and financial global crisis that erupted in 2008.

Therefore, despite the outward absence of global catastrophes such as the "Great Depression", the world economy is seen as very vulnerable in terms of having high chances of getting into a crisis situation, even in terms of its local components.

\section{New management situation}

In modern conditions, a new management situation has arisen, which is characterized by:

- high level of antiquity in a crisis situation (often in many respects in its psychological perception of stakeholders);

- multiplicity of the nature of crisis-forming factors, including completely new ones (such as social, environmental, psychological, informational, imagebuilding, etc.). Some types, on the contrary, have so far weakened, such as military operations or cross-border labor mobility;

- presence of numerous threats and their implementations, generating in the general case a dense and extraordinary stream of future crises. So, for example, due to wide production cooperation and a large nomenclature of equipment (up to hundreds of thousands of assortment items) and a limited alternative, deviations in the discipline of their deliveries theoretically generate no less threat flows;

- $\quad$ high synergies of threats and crises;

- varying degrees of danger of crises for separation;

- "cross-cutting" nature of crises (in terms of vertical hierarchical and horizontal connections and, accordingly, distribution channels);

- $\quad$ significant complication of the connection of crisis-generating factors and crises in terms of delay, non-determinism, etc. the onset of consequences;

- presence of large "shoulders" of the influence of crisis-forming factors on the state of isolation. A lot of insignificant factors give rise to significant fluctuations in the state of separation. That is, these factors generate critical bifurcation points. In the same literature (for example, in some science fiction works created by Isaac Asimov) even introduced the phenomenon of Minimal Possible Impact (MPI), radically changing the future. It is seen as indirectly closely correlating with the principle of least action known in the natural sciences (usually counted from the theoretical achievements of William Hamilton) and its further developments in various physical fields;

- breadth of the spectrum of spaces of indicators of the state of isolation in which the crisis manifests itself.

Therefore, following a number of researchers (Malinetsky, 2001), the management situation with the current separations can be conditionally considered in the development of the corresponding conceptual constructions through the prism of the yet unformed private chaos theory of crises.

\section{Interpretation of the crisis situation}

The concept of crisis is formalized introduced as a state of separation, reflected vector index, when one state index or complex beyond the boundary of the set of it (them) valid values (Zolotova, 2017).

Let there be some vectorial index of the separation state (managed object) $\vec{W} \equiv$ $\left\{\mathrm{w}_{1}, \ldots, \mathrm{w}_{\mathrm{S}}\right\}$, where $\mathrm{S}$ is the number of components of the state index of this managed object, including, possibly, dynamic as derivatives.

They can be quite diverse (Dmitriev \& Novikov, 2018b; Dmitriev \& Novikov, 2019a; Dmitriev, 


\section{AMAZONIA \\ Investiga}

Yekshembiev, Lubaeva, Koval'kov \& Minaev, 2013).

The Figures 1-3 show the conditional trajectories of a certain $\mathrm{j}$-th one-dimensional indicator of the state of isolation and its permissible boundaries (hereinafter, the source is the authors 'own research).

However, trajectory going beyond the borders is one of the most common cases of a possible crisis of separation.

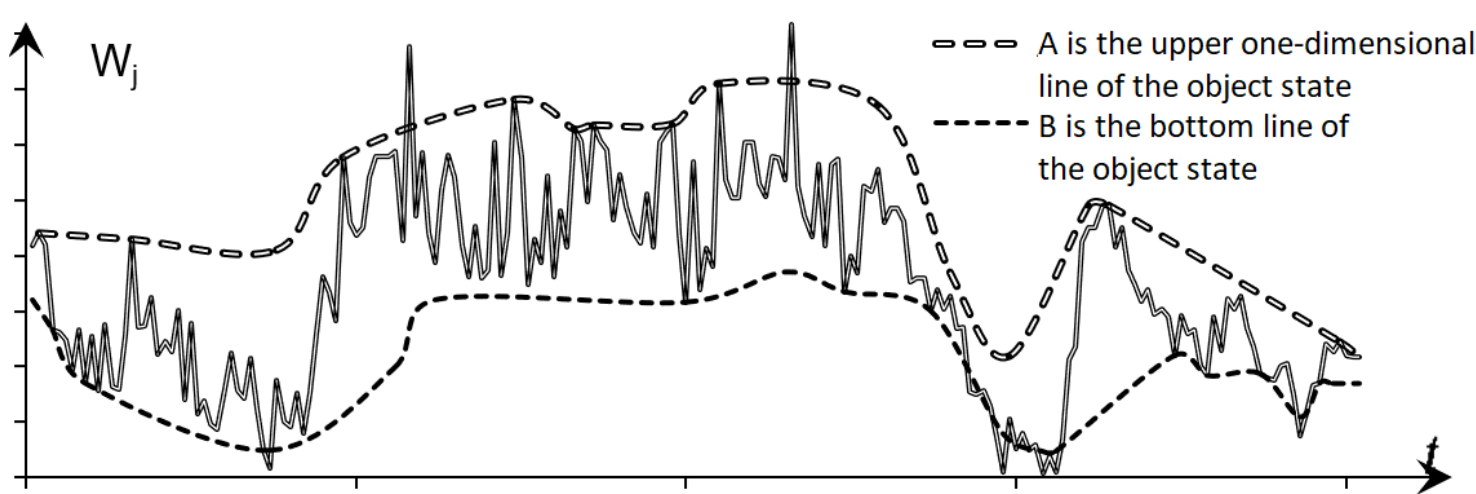

Figure 1. Hypothetical trajectory of one-dimensional state index of the separation and its acceptable boundaries.

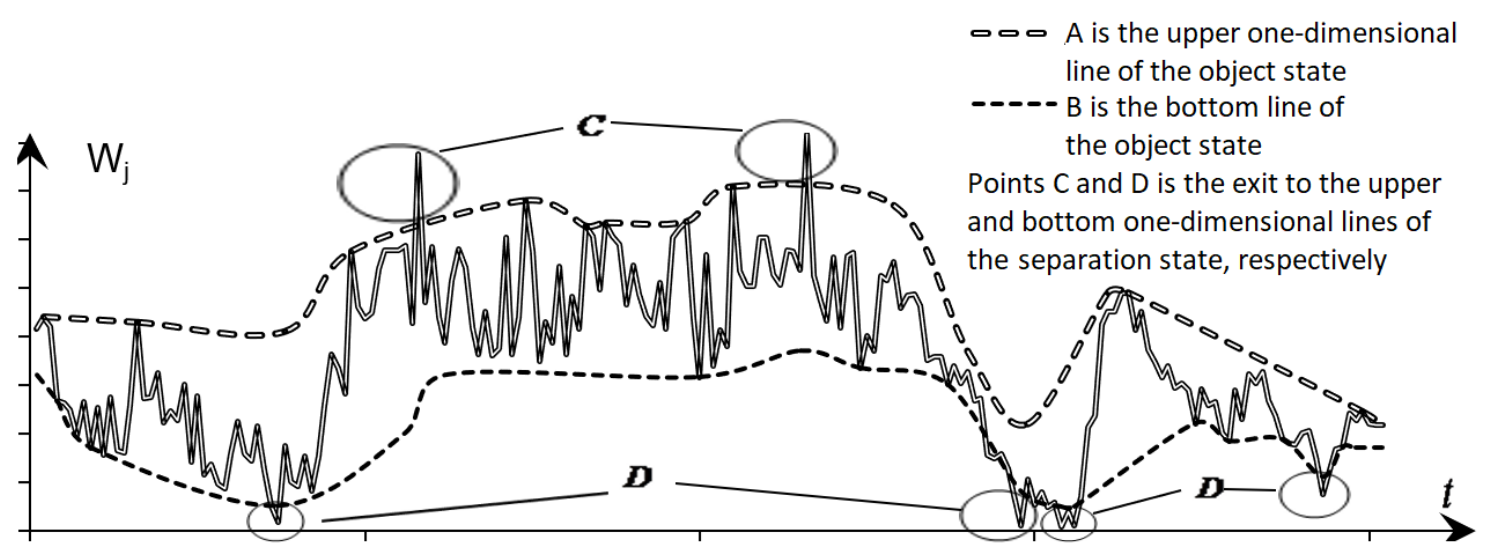

Figure 2. Hypothetical trajectory of a one-dimensional state index of the separation with going beyond borders (case 1)

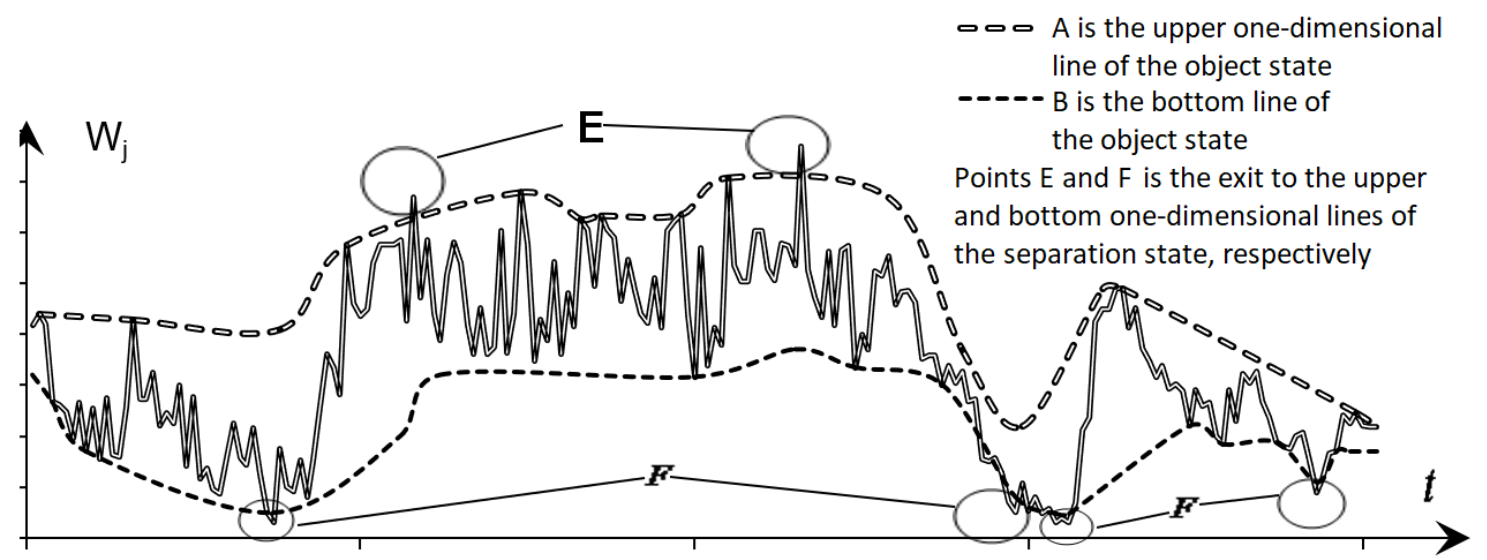

Figure 3. Hypothetical trajectory of a one-dimensional state index of the separation with going beyond borders (case 2) 
In fact, many trajectory "crises" are much wider. So, for example, a crisis may correlate with some phenomena of separation instability (Bloshenko, 2009).

The number of possible crisis situations will correspond, even in the simplest case, to the value $C_{N}^{1}+C_{N}^{2}+\ldots+C_{N}^{N}$ (the number of combinations of possible outputs of state indexes beyond the boundaries of permissible values), where $\mathrm{N}$ is the number of state indexes. Depending on the number of indicators of the state of isolation that go beyond the limits of admissibility, we will distinguish single or group crisis situations.

Naturally, the problem (well-known and difficult to solve) of the "curse of dimensionality" arises if the dimensionality of the space of state indexes is high and aspects of the dynamics of their trajectories are still considered.

The dynamics of crisis situations can be characterized in different sections. It is also necessary to take into account the high probability of transformations of crisis situations from one type to another.

The need to formulate a classification of crisis situations is associated with the absence of an established methodological approach to identifying groups of managerial situations related to many crisis situations. It is not possible to consider simultaneously the variety of causes of crisis situations and the corresponding possible manifestations.

An infinite or excessively large number of crisis situations are unacceptable for development.

Therefore, the number of possible crisis situations should be limited in accordance with the conditions, operating factors and the responses received, consistent with significant isolation properties. Determining the significance of the properties of the state of isolation will allow to determine the sequence of grouping of crisis situations. This, in turn, will reduce the dimensionality of the space of indicators of the state of isolation, which reflect the crisis situation, and ensure the finiteness of many crisis situations for which development is carried out.

There are a large number of comparative measurement procedures for evaluating the results of the functioning and development of isolation (control object). The procedures are due to the multiplicity of properties of the managed object that can be considered, and accordingly to the multiplicity of control objectives. However, it can be said that properties that are not considered as potential management objectives can be neglected. While the properties of the isolation for which the potential characteristics of its state of the control object can be highlighted and the comparative measurement procedures are proposed should be listed.

\section{Classification of crisis situations (crises)}

This classification is multidimensional.

We choose the one that is reflected in one of the previous works as a starting classification scheme (Zolotova, 2017).

Evaluation measures for the manifestation of crisis situations as a reflection of the properties of the control object, correlated with the subject localization, allow to distinguish the following main types by manifestations in the isolation:

- financial and economic crisis situations. Their manifestation is reflected in revenue, valuation of components, raw materials, semi-finished products, and finished products stored in the warehouse, net profit of the enterprise, pessimistic and optimistic assessment of cash balance, consolidated amount of taxes, share of net profit allocated for self-financing of investments and innovations, excess of net assets over authorized capital, etc.;

- production and technical crisis situations. Their manifestation is reflected in the actual and planned capacity of the enterprise, complexity of manufacturing the product range or the general, structural and specific material consumption of manufacturing according to the product range, etc. Also, indicators can be used that reflect equipment performance, operational reliability, use of the working time fund, etc.;

- reputational crisis situations. They are reflected in the views of suppliers and customers on the reputation of management staff, social attractiveness, etc.;

- informational crisis situations. They are reflected in sections of the middle age of computer technology, information security of labor, increase in the volume of information, etc.;psychological crisis situations. By manifestation, they can be correlated with depressive moods, social breakdowns and other events;

- complex crisis situations or hybrid ones. They suggest reflection in terms of 


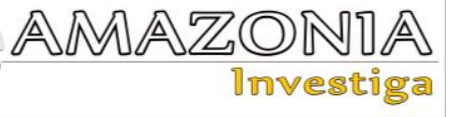

assessment measures inherent in different types of crisis situations.

As a typical discriminatory signs that distinguish between crises situations, as a rule, there are the following accepted things:

- distinguishable nature of deviations of state indexes;

- causality of crisis situations;

- identification of the signs of a crisis in relation to time;

- $\quad$ significance of deviations of state indexes of separation;

- intentionality of crisis situations;

- maliciousness of subjective crisis situations;

- crisis alertness;

- predictability of crisis situations;

- crisis recurrence;

- typability of manifestations.

Apparently, this list is open.

Crisis situations can also be classified by the nature of state indexes of separation on:

- deterministic or inevitable crises;

- $\quad$ stochastic (probabilistic, random) crises;

- uncertainty crises.

The conclusion about the inadmissibility of the state of the managed object is determined on the basis of the consideration of the statics or dynamics of deviations of the state indexes from the given (required) ones. As a rule, absolute deviations, derivatives and analogues of derivatives are distinguishable by the nature of deviations of state indexes (for cases when it is impossible to calculate the derivative, for example, the absence of continuous differentiability). At the same time, typing according to the boundary of the variable makes it necessary to correlate the physical meaning of the signs of a crisis situation and the possibilities of calculating the derivative. The variable itself, the first and the second derivatives of the variable can act as signs. It is impractical to consider the above third derivative variable. Therefore, we will give preference when considering the nature of deviations in the form of derivatives (and its analogues). This choice is justified by the need to monitor not only the rate of change of the characteristics of the state indexes, but also the factors affecting the object.

Values of permissible deviations can be determined by:

- legislative act;
- $\quad$ scientific justification;

- experience;

- $\quad$ subjective decision of management staff.

The basis of the emergence of crisis situations should highlight external, internal and complex causes.

They are also discriminatory factors.

By the magnitude of the deviations of the indicators of state indexes of separation, it is possible to distinguish between crisis situations in light, medium and hard ones.

Crisis-forming factors can be objective and subjective. They are varied by source.

Subjective factors can also be divided into:

- intentional and unintentional;

- favorable and unfavorable.

It is also possible to divide crisis situations into preventable and unpredictable ones (well-known emphasis on force majeure or circumstances of irresistible force).

By the number of repetitions, crisis situations can be divided into primary manifestations and recurring ones. The primary crisis situations are associated with the formation of new industries, changes in the scale of activity, etc.

A certain group of recurring crises can be periodic. Periodic crises most often have conditionally distinguished stages: recession, depression, revitalization, and rise.

Crisis situations can also be divided into unique and typical.

The above features of the crisis situation and the formalized presentation of the crisis situation determine the inevitability of the formation of a universal viewing of separation as a managed object for which crisis situations can be realized. The study of the mutual influence of all influences is feasible in the case of a factorresponse model (Zolotova, 2017).

Thus, the high power of many crises and the possibility of their nontrivial classification typological diversity are undoubted. This set can be represented as a finite one, the elements of which allow the introduction of classification relations of similarity and delimitation. 
Positioning of the recognition system of the crisis isolation state

In case of crisis management of isolations, the conceptual scheme of the feasibility study of crisis managerial decisions is to be applied.

It is advisable to choose the method of a comprehensive feasibility study of a managerial decisions as primary as the basic scheme of anti- crisis management (Dmitriev, 2005; Dmitriev, 2017; Novikov, 2019) (Figure 4).

Within it, the basic management functions should be implemented (estimating of current state, forecasting, comparison, analysis, and optimization).

Crisis recognition affects the first four of the listed typical management functions and thereby closely intertwines with the correct interpretation of controlling (Danilochkina, 2001).

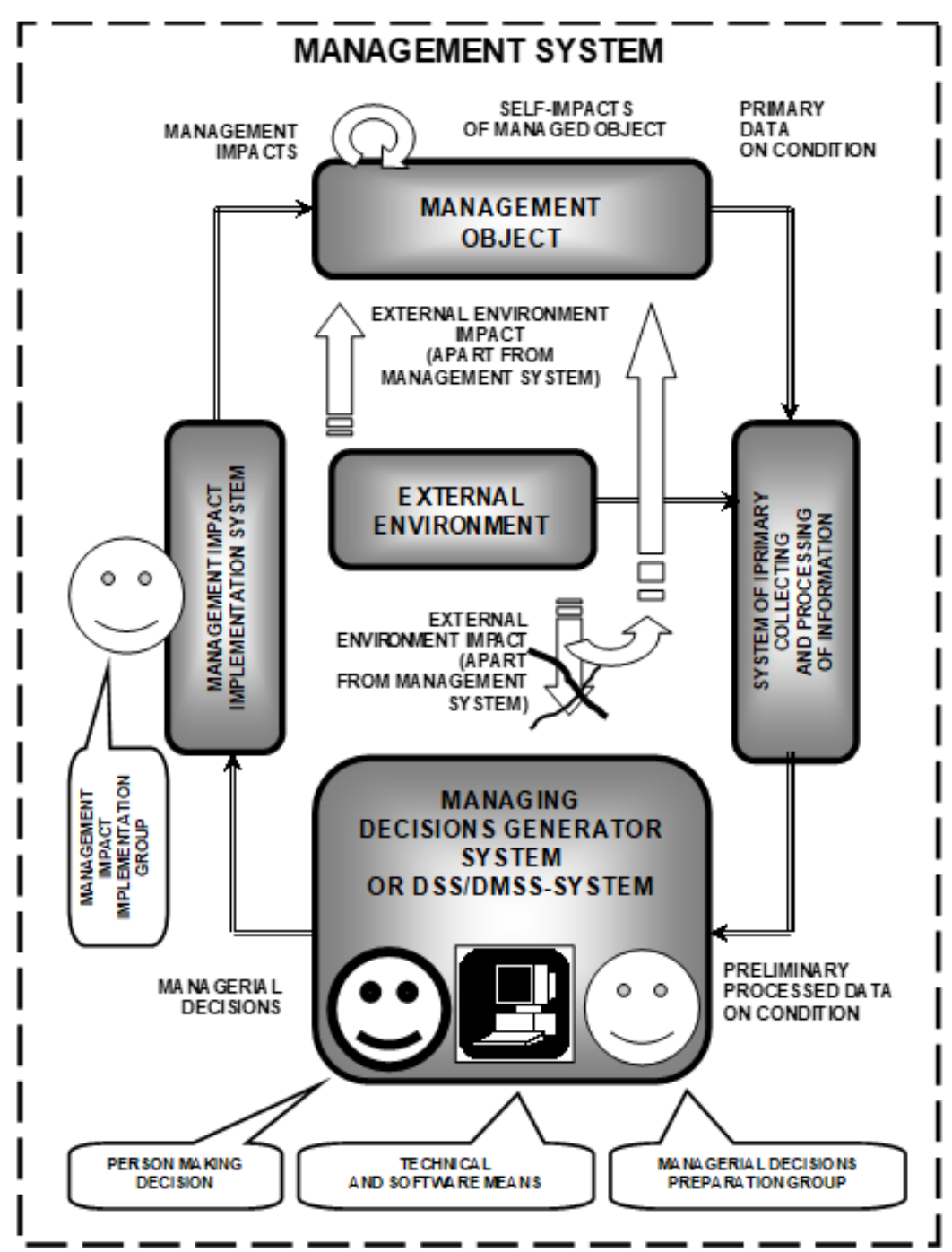

Figure 4. Typical structure of the high-intellectual anti-crisis management system.

Typology of recognition modes and the systemic appearance of mathematical tools for recognizing crisis conditions of isolation

In our case, the classical implementation of functions (Dmitriev, Yekshembiev, Lubaeva, Koval'kov \& Minaev, 2013) is difficult to realize in stereotypical ways due to the huge number of possible crisis situations that defy canonical analytical human-machine processing type sorting and drafting options.

Therefore, at least for the implementation of the functions of comparison and analysis of the expected adverse deviations causality, in some cases it is advisable to use the artificial intelligence apparatus also regarding with the machine reasoning. 


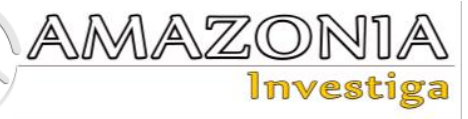

In the course of the research, it was found that it is advisable to recognize crisis conditions in two conceptual ways:

- for the general case, as a rule, medium-term and long-term, as well as situational one, given by management staff in the form of the implementation of the classic DSStechnology (Dmitriev, Yekshembiev, Lubaeva, Koval'kov \& Minaev, 2013; Zolotova, 2017);

- for the case of "everyday" anti-crisis monitoring through the use of an Artificial Intelligence System that supports the recognition of a priori classified crisis situations.

In the second case it should be recognized the following:

- presence of the expected event of a crisis or a complex of crises;

- $\quad$ screening out minor crises;

- ranking of criticality (importance) of expected significant crises;

- typological image of significant crises.

It should be noted that for this Artificial Intelligence System, the following things will be very problematic:

- at least the limited learning of the system: it will be practically a system of situational choice on a priori given "mask" with criteria classification rules;

- docking with a crisis forecasting system based on a system of mathematical models of separation, which may turn out to be a critical link in delay;

- filling the primary information sphereinfosphere (Dmitriev \& Novikov, 2019c);

- choice of focus on the type of error-first or second kind (Zolotova \& Dmitriev, 2018).

If we consider the simplest case when state indexes of separation are beyond certain boundaries, then we can apply rather primitive procedures for pattern recognition (Koval'kov, Dmitriev, Mel'nikov \& Cherkasov, 1981; Koval'kov \& Dmitriev, 1994) or even a generalization of truth tables or automata from Boolean algebra and structure theory. In other cases, it will be necessary to use, apparently, the apparatus of neural networks, but with the inevitable going beyond optimal programming in the process of their synthesis and training.

Experience in application development
The results of the described development were used:

- $\quad$ in forecasting the crisis of a few enterprises and holding structures of high-tech industries in Russia, including as a part of the implementation of projects for their corporatization and optimization of sanitation measures;

- in performing a few feasibility studies of several anti-crisis projects and programs;

- in the realization of a few diploma and dissertation projects mainly within the framework of the educational process at Moscow Aviation Institute (National Research University).

\section{Conclusion}

These considerations give rise to the following observations, conclusions, and recommendations:

- problems of anti-crisis management will be relevant indefinitely for a wide variety of areas of industrial and economic activity over all the world. An appropriate control loop should be introduced for all types of organizational and institutional isolations of the macro-level, meso-level, and microlevel;

- crisis of mentioned separations should be considered comprehensively in many aspects and time points, including future moments, and not be reduced to such as financial insolvency (bankruptcy). Anticrisis management should be organized and implemented, including with a focus on a dense and extraordinary flow of non-trivial crises of a deterministic, stochastic, and uncertain nature. Crises are indicated by the statics and dynamics of state indexes of separation;

- existing backlog and practical experience do not solve anti-crisis management problem;

- $\quad$ separation crises are diverse and classified by a set of discriminatory rules;

- anti-crisis management should be based on the conceptual scheme of the feasibility study of anti-crisis management decisions. This management should be predominantly proactive. Traditional procedures of humanmachine interactive analysis, automated pattern recognition systems according to the criteria for deviation criteria and Artificial Intelligence Systems in terms of machine reasoning can be implemented;

- $\quad$ proposed conceptual approach is seen in part of its basic components as transferable to the 
recognition of crises with not only financial and economic consequences;

- initial development versions have been successfully tested.

\section{References}

Badalova, A. G. (2006). Risk-management of production systems: theory, methodology, implementation mechanisms. Moscow: YanusK.

Bazhutin, A. S. (2009). Anti-crisis management of enterprise development (Dissertation abstract of $\mathrm{PhD}$ in Economics). State Educational Institution of Professional Higher Education "State of Udmurt University" Izhevsk.

Biryukov, A. N. (2015). Methods of neural network modeling to rank taxpayers to determine credit risks. Economic Analysis: theory and practice, 12(411), 58-66.

Bloshenko, A. A. (2009). Technology of integral estimation of stability of financial and economic condition of the enterprise of the Russian industry (Dissertation of $\mathrm{PhD}$ in Economics). Moscow Aviation Institute (State Technical University) MAI, Moscow.

Butrova, E. V. (2021). Features of anti-crisis management of the enterprise in the conditions of digitalization. Journal of economics, entrepreneurship and law, 3(11), 579-590.

Cherner, N. V. (2020). Conceptual foundations of price management in the holding company. Monograph. Moscow: KnoRus.

Danilochkina, N. G. (2001). Controlling as enterprise management tool. Moscow: UNITY. Delibašić, B, Radovanović, S., \& Jayawickrama, U. (2021). Special Issue on AI for Intelligent Decision Support Systems. Guest Editorial Preface - IJDSST, 13(1). Retrieved at: https://www.igi-

global.com/pdf.aspx?tid\%3D267156\%26ptid\%3 D254080\%26ctid\%3D15\%26t\%3DSpecial\%20I ssue $\% 20$ on\%20AI\%20for\%20Intelligent\%20De cision $\% 20$ Support $\% 20$ Systems \&isxn=null

Demchenko, O. F. (2011). Mathematical modelling methodology of organizational structures of the Russian Federation aviation industry. Moscow: KnoRus.

Dmitriev, O. N. (2005). System analysis in management. 5th edition. Moscow: Dobroe Slovo [Good Word].

Dmitriev, O. N. (2017). Strategic problems and directions of developing rehabilitation of managing systems of Russian high-tech complexes. Microeconomics, 6, 5-24.

Dmitriev, O. N. (2018). Conceptual system interpretation of conjuncture management situation in relation to market including operators in such form as high-tech enterprises. Microeconomics, 6, 29-44.

Dmitriev, O. N., \& Dergunov, A. I. (2004). Intrafirm management concerning interdepartment and interpersonal competition within scope of enterprise. In English. Moscow: Gnome and D.

Dmitriev, O. N., \& Novikov, S. V. (2017). Conception of managing of fuzzy-institutional meso-level organizational separations in a context of product projects internationalization. European Research Studies Journal, 20(4), 277-289.

Dmitriev, O. N., \& Novikov, S. V. (2018a). Development of risk insurance area for Russian high-technology enterprises. European Research Studies Journal, 21(4), 386-399.

Dmitriev, O. N., \& Novikov, S. V. (2018b). Economic assessment of federal scientific programs. Russian Engineering Research, 38(4), 326-329.

Dmitriev, O. N., \& Novikov, S. V. (2019a). Verification of feasibility studies at hightechnology enterprises. Russian Engineering Research, 39(9), 780-781.

Dmitriev, O. N., \& Novikov, S. V. (2019b). Unification and convergence of hierarchic structures such as organizational separations and product projects at creation of recommending Decision Support Systems. International Journal of Economics and Business Administration, 7(1), 240-268.

Dmitriev, O. N., \& Novikov, S. V. (2019c). Optimizing the economic information transparency level of high-tech enterprises in the post-industrial globalized economy. International Journal of Economics and Business Administration, 7(3), 25-56.

Dmitriev, O. N., \& Zolotova, V. A. (2020). Formalized Conceptual Rule to Interpret Crisis State of Organizational and Economic Separation for Micro-level and Meso-level. Amazonia Investiga, $\quad 9(25), \quad 327-336$. https://amazoniainvestiga.info/index.php/amazo nia/article/view/1076

Dmitriev, O. N., Yekshembiev, S. Kh., Lubaeva, J. I., Koval'kov, Ju. A., \& Minaev, E. S. (2013). Strategic management concerning corporation (fundamental and applied problems). 2nd iss. (revised and expanded). Moscow: Dobroe Slovo [Good Word].

Fal'ko, S. G., \& Boyko, V. P. (2019). Controlling innovative projects in the rocket and space industry: Monograph. Moscow: Russian Association of Controllers.

Fal'ko, S. G., Volochienko, V. A. \& Vasiliev, S. V. (2019). Controlling: preparation of management decisions in real time: Monograph. Moscow: Russian Association of Controllers. 


\section{$\frac{\text { AMAZONDA }}{\text { Dnvestiga }}$}

Forrestor, D. (1971). Fundamentals of Enterprise Cybernetics. Moscow: Progress.

Grishin, I. Yu., Timirgaleeva, R. R. (2016). The Application of artificial intelligence methods for forming industry management systems. Modern Information Technologies and IT-education, 1(12), 115-120.

Guruva, V. A. (2019). Provision of government support to the financial rehabilitation of enterprises using artificial intelligence technology. Scientific bulletin: finance, banks, investments, 2, 56-64.

Jons, M. T. (2018). All application programming. Moscow: DMK: Press.

Kanashchenkov, A. I., Dmitriev, O. N., Koval'kov, Ju. A., Dergunov, A. I. \& Minaev, E. S. (2005). Management concerning interaction of enterprise with federated system of accessory subcontractors. Moscow: Dobroe slovo [Good Word].

Koval'kov, Ju. A., Dmitriev, O. N., Mel'nikov, M. K., \& Cherkasov, Yu. M. (1981). Forecasting state indexes in ACS of quality and reliability. Methodical materials, series "Economics and management systems", 4(48). Moscow: Central Research Institute "Electronics".

Koval'kov, Ju. A., \& Dmitriev, O. N. (1994). Effective Marketing Technologies. Moscow: Mashinostroenie [Mechanical engineering].

Kulikovskiy, K. L., \& Petrov, D. V. (2008). Usage of artificial neural networks in management decision support systems of industrial enterprises. Bulletin of Samara State Technical University. Series: Technical Sciences, 2(22), 38-42.

Kuznetsova, A. V., Samigin, P. S., \& Radionov, M. V. (2016). Artificial intelligence and information security of society. Monograph. Moscow: Ruscience.

Lapenkov, V. I. (2001). Management methodology of the current liquidity of a manufacturing enterprise (Dissertation of Fulldoctor in Economics). Instituto de Aviación de Moscú, Moscow.

Malinetsky, G. G. (2001). Chaos. Structures. Computational experiment. Introduction to nonlinear dynamics. 3rd iss. Moscow: UPSS.

Minaev, E. S., \& Panagushin, V. P. (1998). Anticrisis management: Studies. Moscow: PRIOR. Nagornov, M. A. (2008). Enterprise management in crisis situations (Dissertation abstract of full- doctor in Economics) Saratov State Social and Economic University, Irkutsk.

Novikov, S. V. (2019). Clusters in modern innovations of the economy of the Russian Federation. Espacios, 40(25), 7-14.

Pershina, E. S., \& Daragan, S. V. (2018). From big data to advanced analytics in the tourism industry. Scientific Bulletin MSIIT, 2(52), 60-69.

Popov, A. (2005). Anti-crisis management. Moscow: High School.

Russell, S. J., \& Norvig, P. (2018). Artificial Intelligence: A Modern Approach (AIMA). Translate by Ptitsyn K. A. 2nd iss. Moscow: Williams.

Solodukhin, D. N. (2008). Financial rehabilitation of industrial enterprises in the conditions of bankruptcy (Dissertation abstract of full-doctor in Economics). Academia de Administración Pública de Rusia bajo la presidencia de la Federación de Rusia, Moscow. Tsvikilevich, N. G. (2009). The mechanism of overcoming economic crisis in the industrial sector of the region (Dissertation abstract of fulldoctor in Economics). Udmurt State University, Izhevsk.

Wiener, N. (1983). Cybernetics. Moscow: Science.

Yankovskaya, N. G. (2009). Management of industrial enterprises in the conditions of economic crisis: innovative aspect (Dissertation abstract of full-doctor in Economics). Far Eastern State University of Transportation, Khabarovsk.

Zolotova, V. A. (2017). Management problems and tasks of the formation of management innovation anti-crisis program in the Russian high-tech industry. Monograph. Moscow: KnoRus.

Zolotova, V. A., \& Dmitriev, O. N. (2018). Conceptual interpretation of first and second kinds

of errors at management mode selection under conditions of its possible crisis state. Russian Engineering Research, 38(4), 291-294.

Zykov, S. V. (2016). Crisis Management for Software Development and Knowledge Transfer. Springer Series in Smart Innovation, Systems and Technologies. Switzerland: Springer.

Zykov, S. V. (2018). Managing Software Crisis: A Smart Way to Enterprise Agility. Cham: Springer. 